\title{
Relationship between Frequencies of Pressure Oscillations and Rotor Speed under Rotating Stall
}

\author{
Y. Levy', J. Pismenny ${ }^{2}$, A. Reissner ${ }^{3}$ and W. Riess ${ }^{4}$ \\ 'Faculty of Aerospace Engineering, Technion, 32000 Haifa, Israel, \\ e-mail: levyy@aerodyne.technion.co.il \\ ${ }^{2}$ Faculty of Aerospace Engineering, Technion, 32000 Haifa, Israel, \\ e-mail:aeryljp@aerodyne.technion.co.il \\ ${ }^{3}$ Institute for Turbomachinery, University Hannover, Germany; \\ e-mail:Reissner@ifs.uni-hannover.de \\ ${ }^{4}$ Institute for Turbomachinery, University Hannover, Germany
}

\begin{abstract}
The correlation between the frequencies of pressure oscillation $\omega_{o s c}$ and the rotor speed (frequencies of rotor rotation $\omega_{R R}$ ) under established rotating stall were determined by three methods: directly from the time diagram of the oscillation process, from the behavior diagram of parameters in space and time and from frequency characteristics. In total accordance with the Theory of Nonlinear Oscillation, by all methods of analysis, the links are in the form of integer ratios: $\omega_{o s c} / \omega_{R R}=1: 2$ (for $n /$ $n_{d}=0.6$, where $n$ - rotor speed in the experiment and $n_{d}$ - rotor speed from data-sheet) and $\omega_{o s c} / \omega_{R R}=3: 7$ (for $n / n_{d}=0.8$ and $\mathbf{0 . 9 5}$ ). The phases of parameter oscillations in the transverse cross-section are equal to the sensor angles in compressor stator. This is in agreement with the theoretical concept of single-cell configurations of rotating stall.
\end{abstract}

Keywords: rotating stall, rotor speed, pressure oscillation

\section{Object}

It is well known that the region of the stall cell in a rotor blade row of an axial compressor appears to move relative to the blades in the opposite direction to the rotor rotation with a speed less than the circumferential velocity of the blades. Different values for the relation between rotor speed and the rotational frequency of pressure oscillation are also given in literature: "Mode Speed $20 \%$ ", "Cell Speed $40 \% "$ (Camp and Day, 1997), "Speed 33\%", "Speed 44\%" (Day et al., 1999), "angular propagation speed of rotating stall" $0.333,0.667$, 0.909 (Ariga et al., 1987), etc. According to the Theory of Nonlinear Oscillation (see, for example, Kahn and Zarmi, 1998, Pismenny, 1978, 1987,
Rosseau, 1987), the frequency relationships under resonance may be considered in the form of integer ratios (in the cases cited above the ratios are 1:5, 2:5; $1: 3,4: 9 ; 1: 3,2: 3,10: 11$, respectively).

In recent years attention has mainly centered on the emergence, inception and onset of rotating stall in compressors and engines (see, for example, Day and Freeman, 1994; Camp and Day, 1997; Day et al., 1999). In our opinion, the stabilized stage of the rotating stall process also merits special consideration. In particular, the links between the frequencies of pressure oscillation and the rotor speed, the links between the phases of pressure oscillation and angles of the sensors on the compressor casing (in the transverse cross-sections), and the change of the pressure oscillation phases in

Presented at the $5^{\text {th }}$ Conference on Turbo Compressors in Industrial Applications, September 18-19, Duisburg, Germany 
the direction from the inlet to the outlet of the compressor (in the longitudinal direction) should be considered.

In earlier experimental investigations (Walbaum, 1999) it has been shown that in the examined multistage axial compressors, with compressible flow conditions at rotational speeds above $\sim 50 \%$ design speed, only single-cell configurations of rotating stall exist and that the rotating stall extends through the complete machine in a stable manner.

In this paper we consider only two issues:

1) the links between the frequencies of pressure oscillation and the rotor speed from the position of the Theory of Nonlinear Oscillation and

2) the links between the phases of pressure oscillation and angles between the sensors on the compressor casing.

\section{Technical characteristics of the axial test compressor}

For investigative purposes a test compressor with small geometric size and characteristics similar to industrial machines was used.

Fig. 1 shows a longitudinal cross-section, of special significance for the rotating stall

investigations - the adjustable ring-throttle is directly at the outlet. This makes a very small pressure side system volume, so that surge cannot occur. The test compressor can be operated in stable rotating stall without undue risk.

The main geometric and design data are presented in Table 1.

The test compressor is operated in an open loop with air filter, air flow meter and inlet throttle. It is driven by a direct current motor with variable speed.

Table 1

Technical data of test compressor

\begin{tabular}{|l|l|}
\hline Nominal speed & $18000 \mathrm{rpm}$ \\
\hline Nominal mass flow & $14.1 \mathrm{~kg} / \mathrm{s}$ \\
\hline Inlet pressure & $0.6-1.0 \mathrm{bar}$ \\
\hline Isentropic efficiency & 0.88 \\
\hline Total pressure ratio & 2.95 \\
\hline Number of stages & 4 \\
\hline Stage pressure ratio & 1.3 \\
\hline Tip diameter (const) & $340 \mathrm{~mm}$ \\
\hline Blade length & $90-45 \mathrm{~mm}$ \\
\hline Peripheral speed (tip) & $320 \mathrm{~m} / \mathrm{s}$ \\
\hline Axial velocity & $190-150 \mathrm{~m} / \mathrm{s}$ \\
\hline Blade clearance & $0.8-0.4 \mathrm{~mm}$ \\
\hline
\end{tabular}

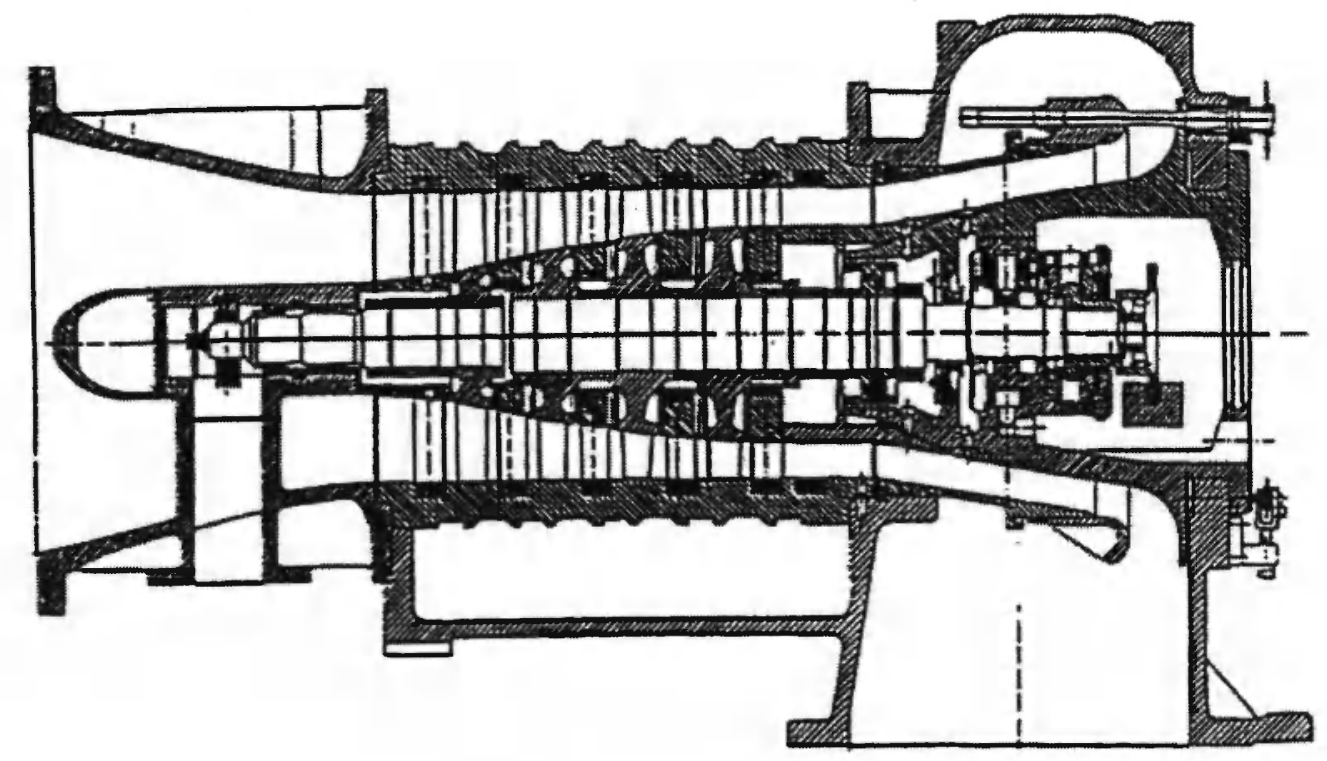

Fig. 1: Longitudinal cross-section of test compressor 


\section{Data acquisition system}

For the measurement of the unsteady static pressure during the rotating stall, miniature pressure sensors, flush mounted in the casing, in front and behind all four rotor blade rows, have been applied. In front and behind rotor 1 , five sensors are distributed around the circumference. In the following measuring planes three sensors are placed.

The sensors are spaced at unequal distances at the circumference, because this simplifies an unambiguous interpretation of the signals, as far as number, direction and speed of movement of stall cells are concerned.

The signals are sampled at a frequency of 50 $\mathrm{kHz}$, then amplified, passed through a $20 \mathrm{kHz}$ lowpass filter and recorded simultaneously on a multichannel transient recorder. One trigger signal per revolution is recorded as well.

\section{Analysis methods for the measured data}

Characteristics of the oscillating flow pressure during rotating stall, were determined for several rotor speeds $\left(n / n_{d}=0.6,0.8,0.95\right)$. Simple and practical methods may be used simultaneously to study the unsteady processes (in space and time) in systems with compressors (Pismenny and Levy, 2000):

- visual inspection of the measured pressure, presenting the information over the whole circumference of the compressor with the information from the first sensor repeated again (after the last sensor). In this way it is possible to observe a complete cycle of the flow parameter change.

- visual inspection of the measured pressure in time and space, by repetition of the transducer information. By this means it is possible to observe the evolution of the rotating stall in space and time simultaneously, thereby also improving the precision of the time measurements.

The links between the frequencies of oscillations of the flow pressure $\omega_{a s c}$ and rotor speed (frequencies of rotor rotation $\omega_{k R}$ ) under established rotating stall were determined by three methods:

- directly from the time diagram of the oscillation process,

- from the behavior of the pressure in space and time,

- from the signal frequency spectra characteristics.

Links between installation angles of pressure sensors in transverse cross-section of compressor stator and phases of pressure oscillation were determined with the aid of correlation functions between the pressure signals, measured by sensors in this cross-section.

\section{Results}

1. Determination of the links between the pressure oscillation and rotation frequencies directly from the time diagram of the oscillation process is given through comparison of the number of oscillation periods of the pressure sensor signals with that of complete revolutions (oscillation periods) of the rotor. For determination of these links it is sufficient to have the time diagrams of two parameters: 1) one of the pressure sensors and 2) the rotor revolution sensor. The ratio $T_{O S C} / T_{R R}$ and the reciprocal ratio $\omega_{o s c} / \omega_{R R}$ are obtainable by counting the number of periods measured on each of these sensors over the same time interval. This is shown in Fig. 2 (for $n / n_{d}=0,6$ ), Fig. 3 (for $n / n_{d}=0.8$ ) and Fig. 4 (for $n / n_{d}=0.95$ ). From these figures it follows that

$$
\begin{array}{ll}
\text { for } n / n_{d}=0.6 & \omega_{\text {osc }} / \omega_{: R}=1: 2 ; \\
\text { for } n / n_{d}=0.8 & \omega_{a s c} / \omega_{R R}=3: 7 ; \\
\text { for } n / n_{d}=0.95 & \omega_{a s c} / \omega_{R R}=3: 7 .
\end{array}
$$

2. Behavior of pressure in space and time. It should be noted that under established rotating stall the pressure change pattern repeats continuously, so that the pressure signal of the first sensor in a cross-section can be inserted behind that of the last one again at a $360^{\circ}$ angle. Simple and practical methods may be used to study the unsteady 


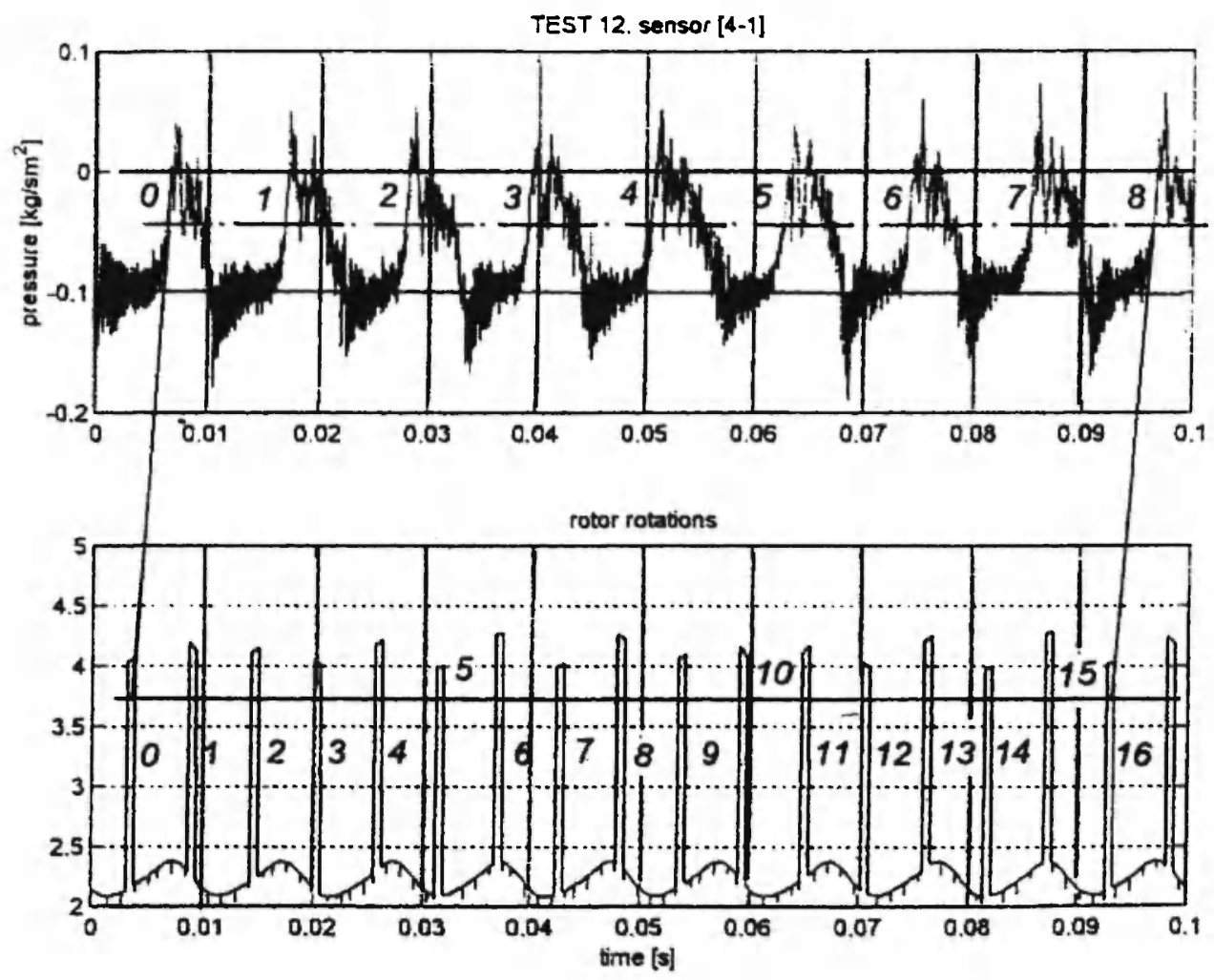

Fig. 2: Determination of $T_{O S C} / T_{R R}=2: 1$ for $n / n_{d}=0.6 .1$ sensor in front of rotor 1

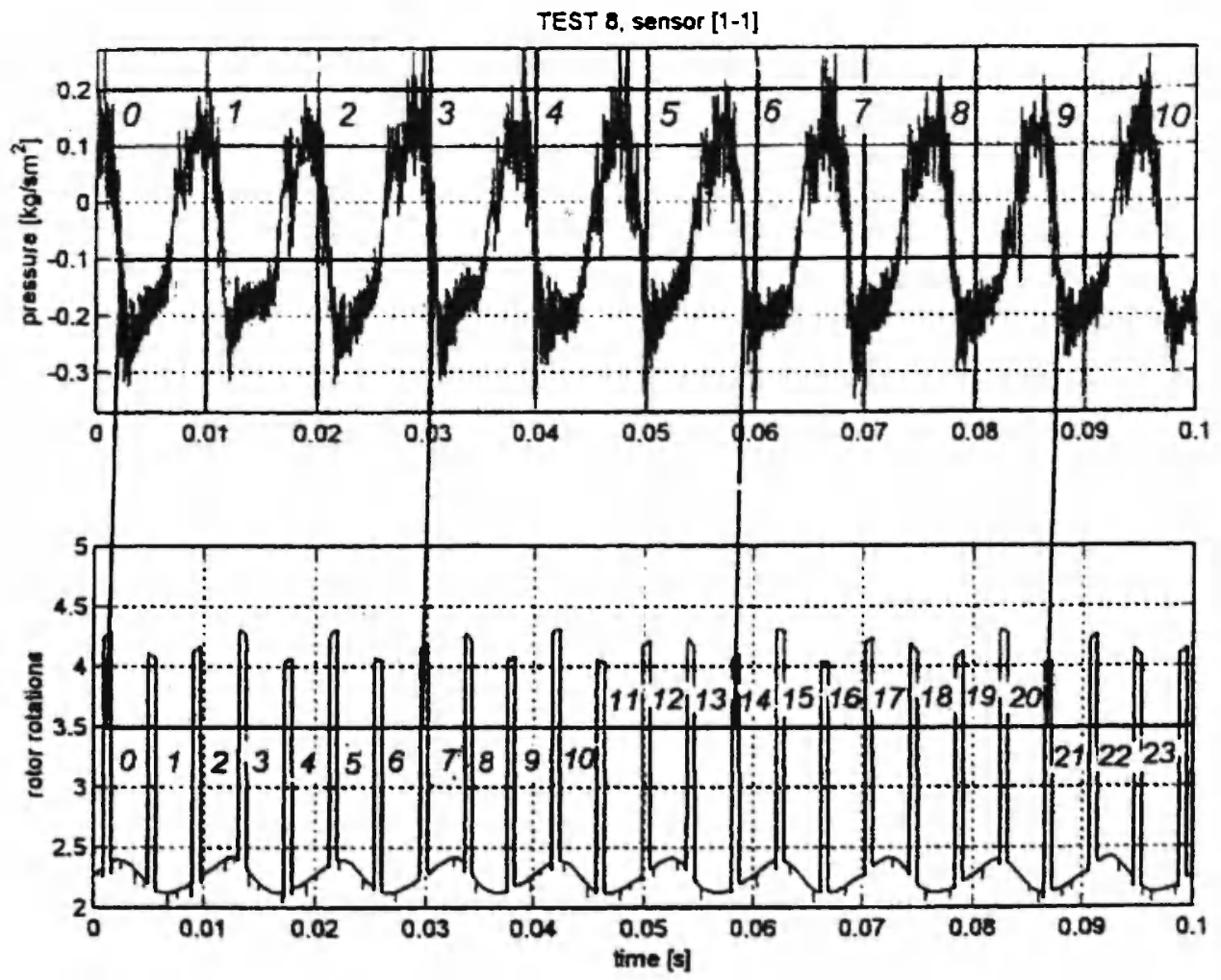

Fig. 3: Determination of $T_{O S C} / T_{R R}=7: 3$ for $n / n_{d}=0.8$. 1 sensor in front of rotor 1 


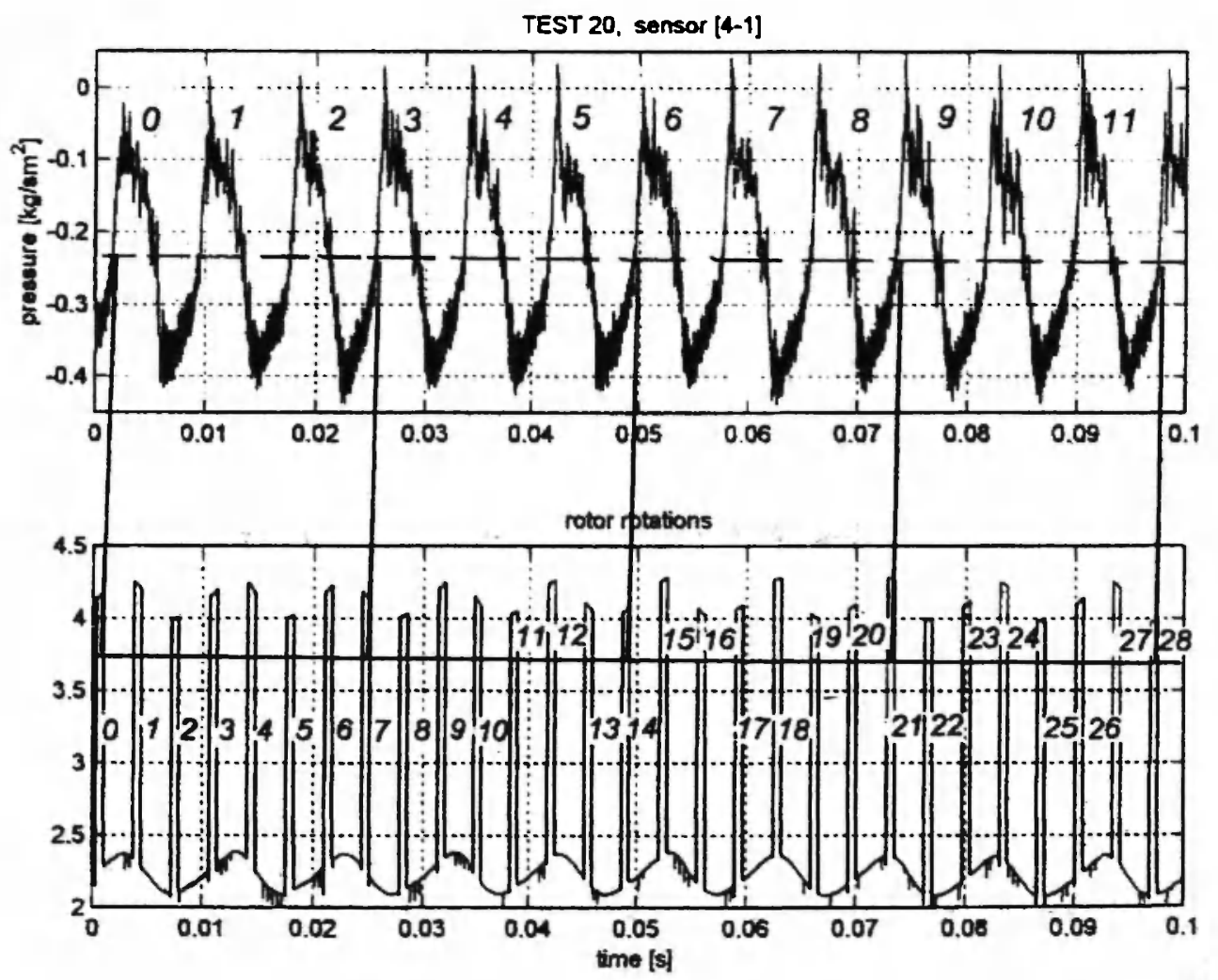

Fig. 4: Determination of $T_{O S C} / T_{R R}=7: 3$ for $n / n_{d}=0.95 .1$ sensor in front of rotor 1

(in space and time) process in compressors:

- presentation of the information from all pressure sensors mounted at the circumference (starting with first sensor and ending with first sensor). In this way it is possible to visualize the complete period of parameter change.

- the method of expanded visibility of the process, in time and space, by repetition of the transducers information. By this means it is possible to observe the evolution of the rotating stall in space and time simultaneously, thereby also improving the precision of the time measurements.

Typically, in experimental investigation of rotating stall, several pressure sensors (commonly 46) are positioned around the circumference of the outer casing. In the present investigation, the sensors are distributed irregularly in the cross-sections of the compressor. Consequently the spacings between the pressure lines in the time diagrams were adjusted according to their angular position.

The behavior of pressure in the first transverse cross-section during rotating stall is shown in Figs. 5, 6 and 7. All diagrams are plotted on the same time scale for 3 complete cycles (1080 degrees) of the pressure changes in the circumferential direction (the readings of all sensors are repeated 3 times and the lines of sensor [4-1] - 4 times). In Figs. 5, 6 and 7 the lines $A B$ are lines of constant time, lines $B C$ are lines of constant compressor angle and lines $A C$ are lines of constant phase of pressure oscillations. As may be seen from these figures, three complete cycles of pressure oscillation correspond to six rotor revolutions in Fig. 5 and seven rotor revolutions in Figs. 6 and 7. Thus, by this method we obtain the same result as directly from the time diagram:

$$
\begin{array}{ll}
\text { for } n / n_{d}=0.6 & \omega_{0 . s c} / \omega_{R R}=1: 2 ; \\
\text { for } n / n_{d}=0.8 & \omega_{0 . s c} / \omega_{R R}=3: 7 ; \\
\text { for } n / n_{d}=0.95 & -\omega_{0 . s c} / \omega_{R R}=3: 7 .
\end{array}
$$




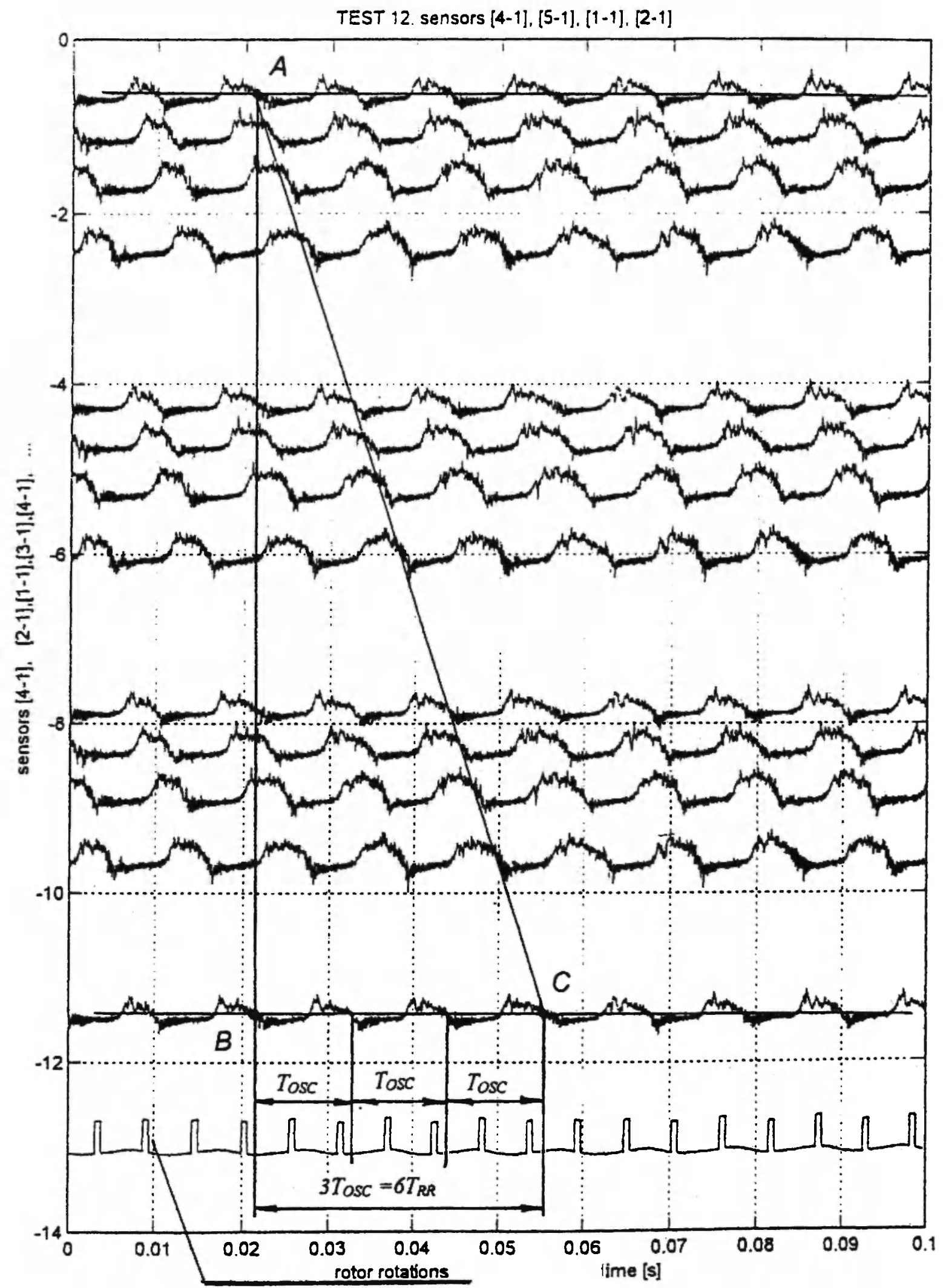

Fig. 5: Determination of $T_{O S C} / T_{R R}=2: 1$ for $n / n_{d}=0.6 .4$ sensors in front of rotor 1 
TEST 8. sensors [4-1], [5-1], [1-1], $[2-1]$

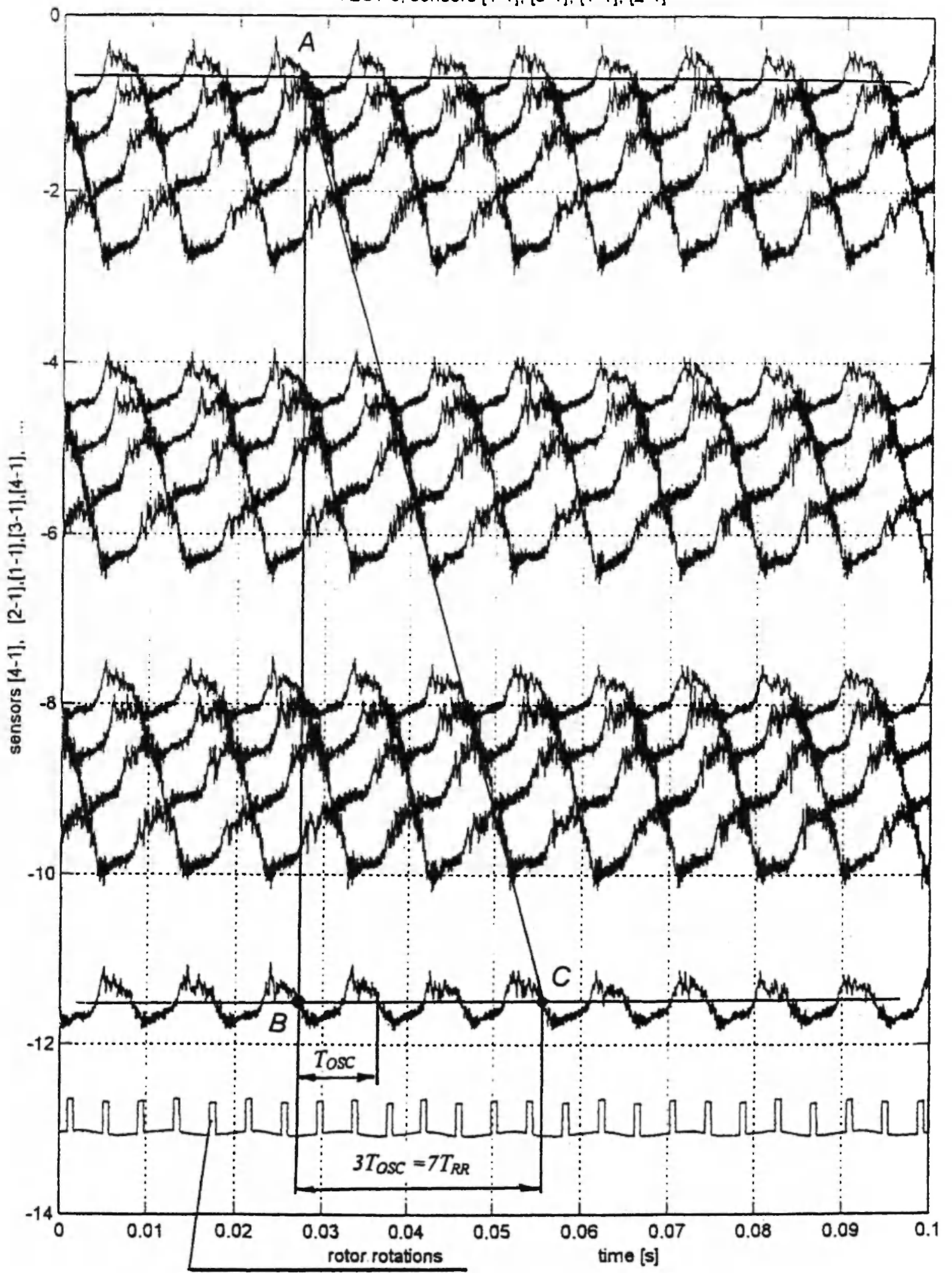

Fig. 6: Determination of $T_{O S C} / T_{R R}=7: 3$ for $n / n_{d}=0.8 .4$ sensors in front of rotor 1 
TEST 19, sensors [4-1], [5-1], [1-1], [2-1]
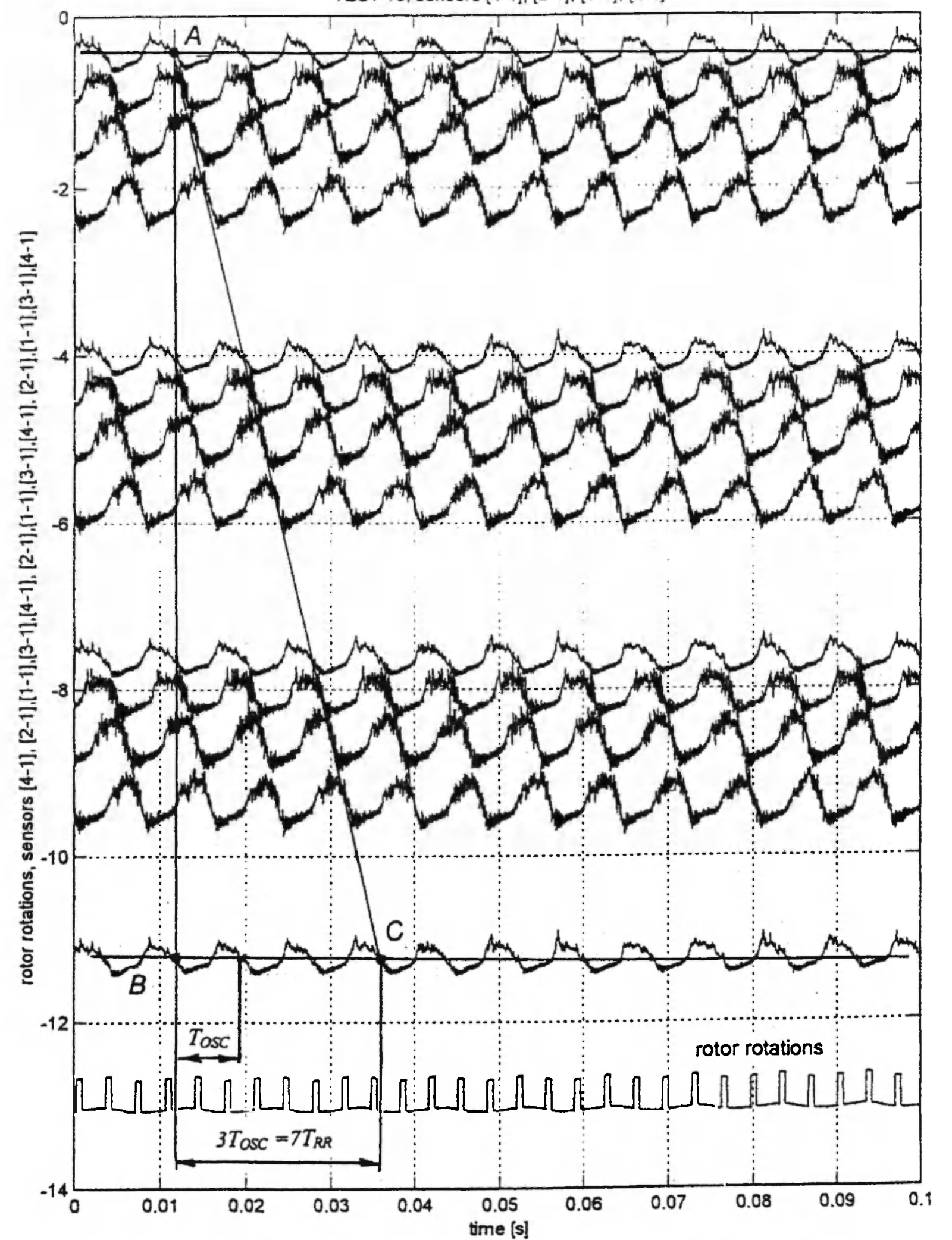

Fig. 7: Determination of $T_{O S C} / T_{R R}=7: 3$ for $n / n_{d}=0.95 .4$ sensors in front of rotor 1 
3. Frequency characteristics of pressure oscillation. A standard method of periodical signal presentation in the frequency domain is in the form of the spectra of these signals. We look for a similar frequency in the spectra of the pressure sensor signal and of the rotor revolution sensor signal. Thereafter we determine the harmonic numbers of these frequencies with respect to each of these two signals.

Amplitude-frequency characteristics of signals are shown as an example in Fig. 8 (for $n / n_{d}-0.6$ ). As a reference the diagram also shows the amplitude-frequency characteristics of the (square) signal of the rotor rotation sensor, hence not of the rotor speed. Because the rotor rotation sensor frequency characteristic includes not only the first, but also other harmonics of speed of rotor rotation it is very convenient for comparison with frequency characteristics of the pressure sensor signals. The diagram shows that the amplitude-frequency characteristics of all pressure sensor signals in one cross-section for each rotor speed have similar harmonics. Similar investigations have been made for $n / n_{d}=0.8$ and $n / n_{d}=0.95$.

\section{Determination of links from frequency spectra}

The frequency characteristics of the pressure sensor signals and rotor revolution sensor signals are shown in Fig. 8 (for $n / n_{d}=0.6$ ), Fig. 9 (for $n / n_{d}=$ 0.8 ) and Figs 10, 11 (for $n / n_{d}=0.95$ ) in a form that is suitable for determination of the sought links. For this purpose, the numbers of the first and subsequent

TEST 12. Frequency Characteristics
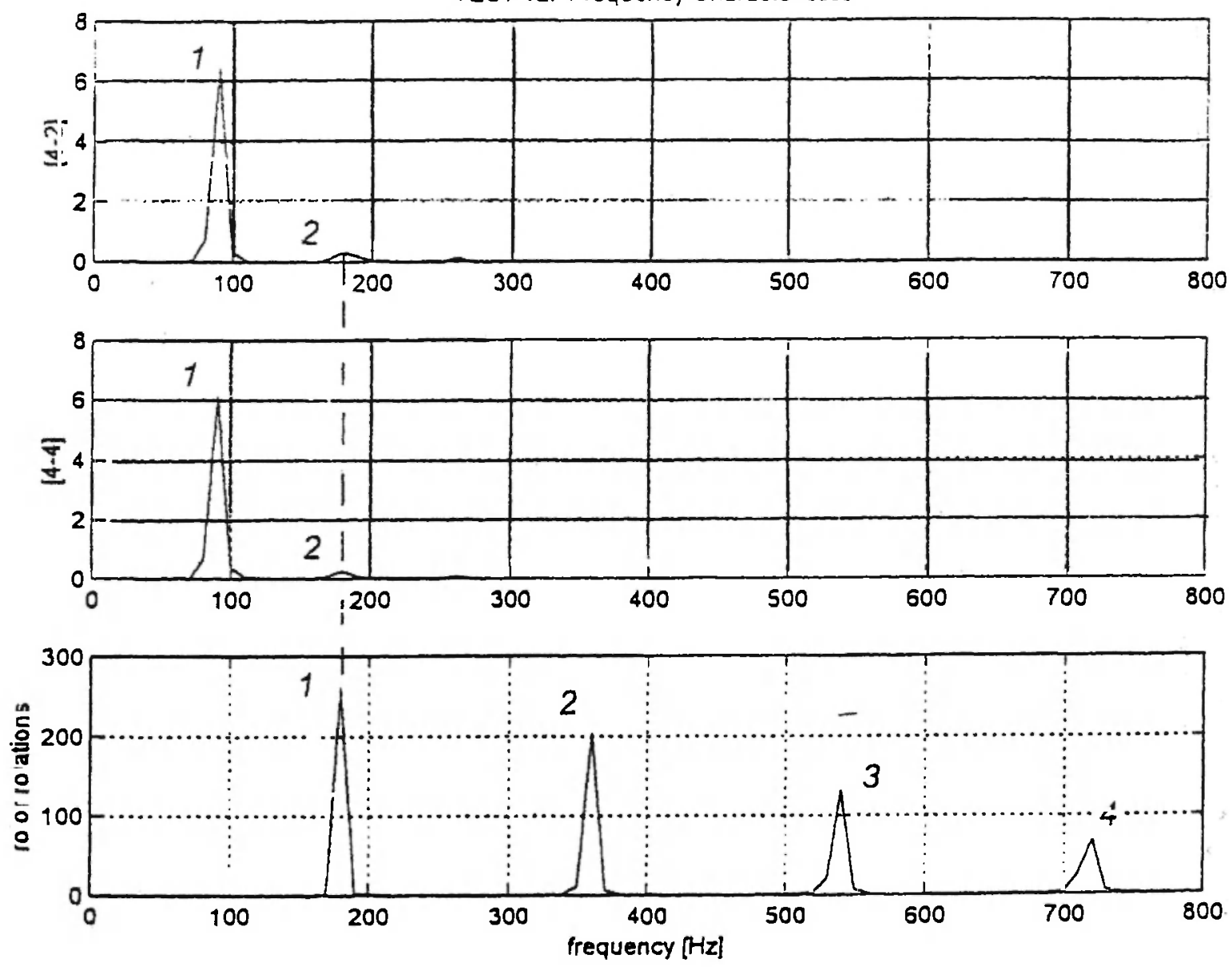

Fig. 8: Determination of $\omega_{0, s c} / \omega_{R R}=1: 2$ from frequency characteristics for $n / n_{d}=0.6$ 

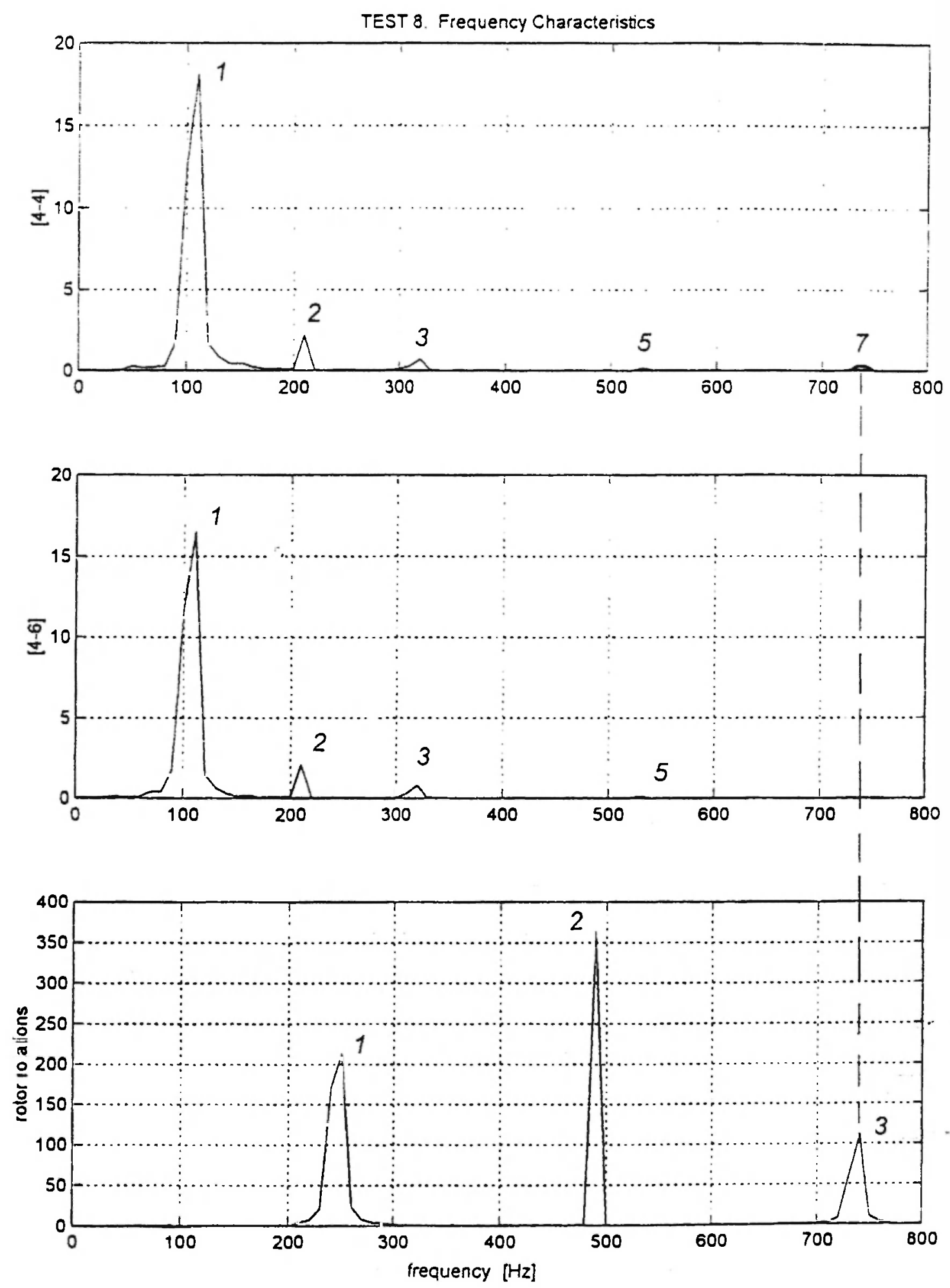

Fig. 9: Determination of $\omega_{o s c} / \omega_{R R}=3: 7$ from frequency characteristics for $n / n_{d}=0.8$ 
TEST 19. Frequency Characteristics
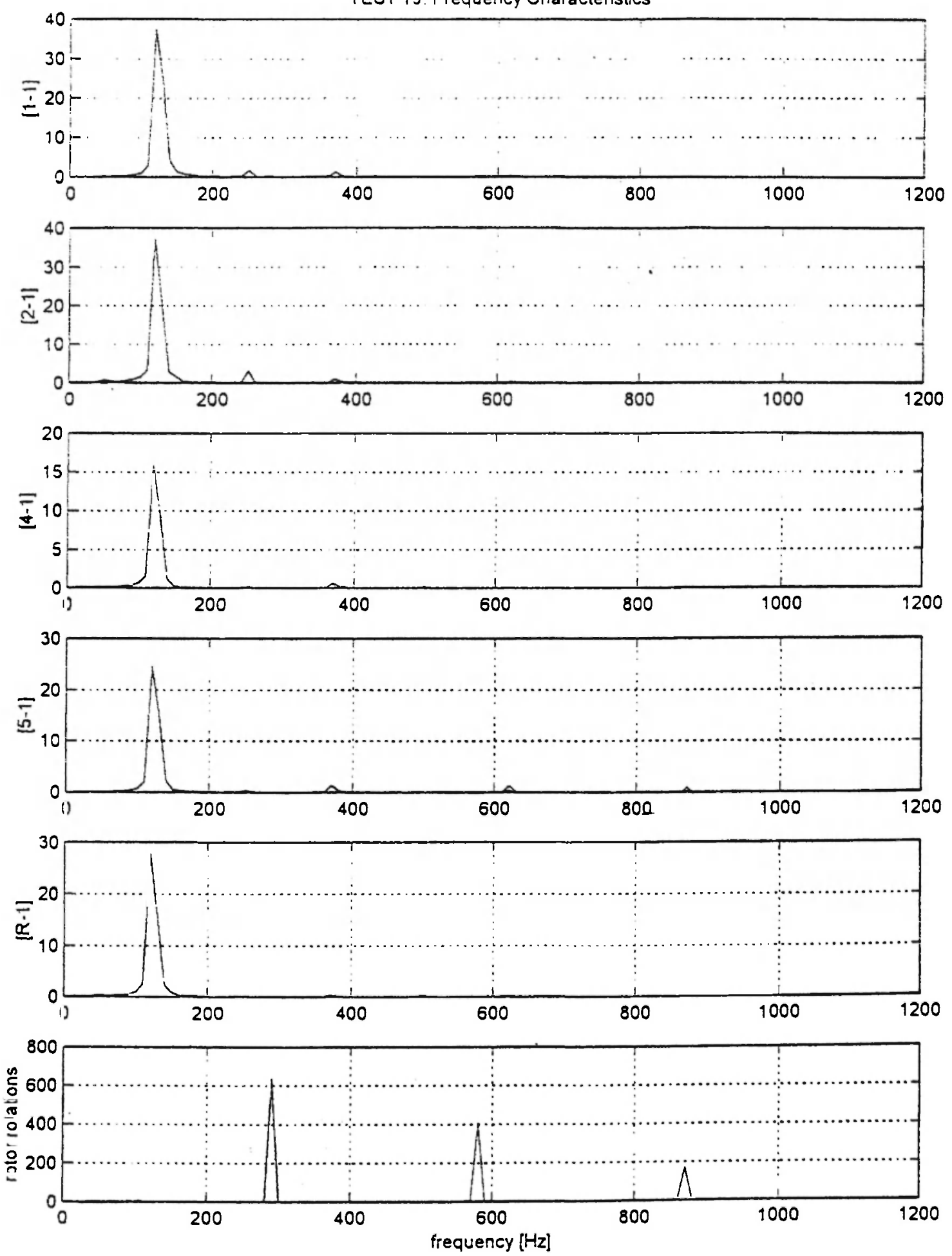

Fig. 10: Determination of $\omega_{0 s c} / \omega_{R R}=3: 7$ from frequency characteristics for $n / n_{d}=0.95$ 

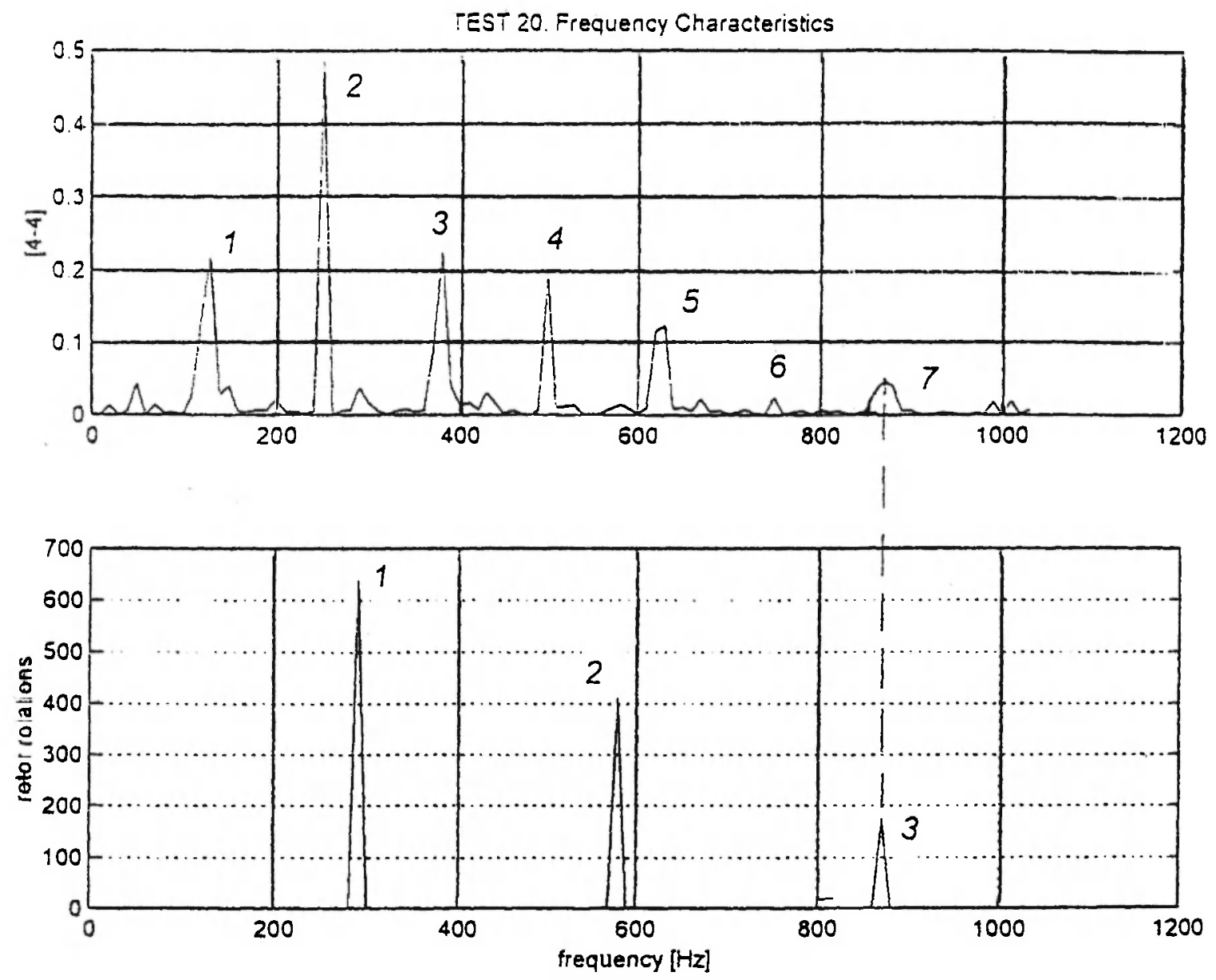

Fig. 11: Determination of $\omega_{t s c} / \omega_{R R}=3: 7$ from frequency characteristics for $n / n_{d}=0.95$ (on a great scale)

harmonics are noted on each characteristic. As seen in Fig. 9 not all harmonics in the spectrum are present and are not essential for counting (for example, in this figure the fourth and sixth are absent). It is important only that their spacing is equal to, or is a multiple of, the spacing between the first and second harmonics. It should be noted that the frequency range should be sufficient so as not to face the risk of important ratios between the frequencies remaining undetected due to a too narrow frequency band. As Fig. 8 shows, the first harmonic of the rotor revolution sensor equals the second harmonic of the pressure sensor, i.e. $\omega_{\text {osc }} /$ $\omega_{R R}=1: 2$ for $n / n_{d}=0.6$. In Figs 9, 10 and 11 the third harmonic of the rotor revolution sensor equals the seventh harmonic of the pressure sensor, i.e. $\omega_{v s c}$ $/ \omega_{R R}=3: 7$ for $n / n_{d}=0.8$ and 0.95 . Thus, we obtain the same result by this method as well. An additional merit of this and the two preceding methods is that determination of $\omega_{o s c} / \omega_{R R}$ does not require an exact determination of $\omega_{a s c}$ and $\omega_{R R}$.

\section{Links between angles of pressure-sensors' location in transverse cross-section and phases of pressure oscillation}

These links were determined in the form of phase differences between the pressure signals in crosssections 4, 5, 1, 2 (in front of rotor 1).

Fig. 12 shows the angular positions of the pressure transducers in the compressor casing. In front of and behind rotor 1 transducers 1 to 5 are installed. The measuring planes in front of and 


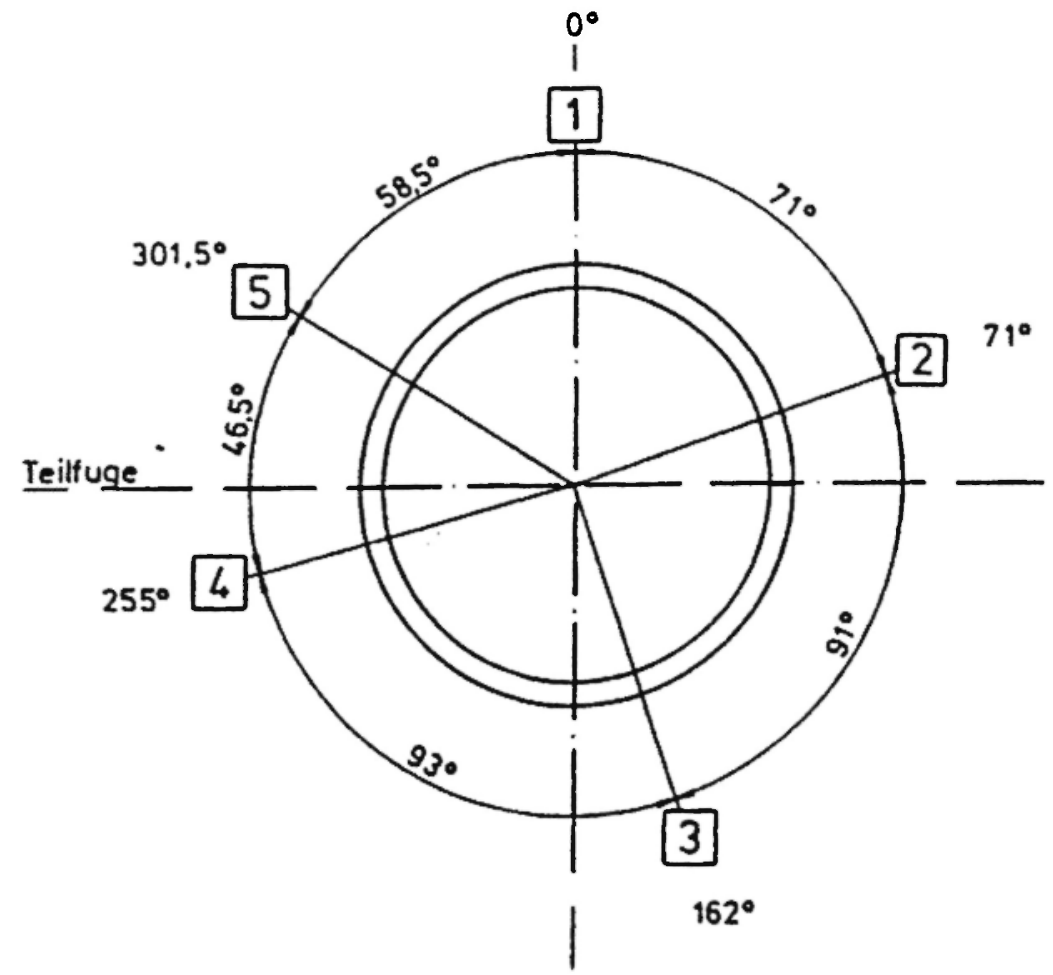

Fig. 12: Positions of pressure sensors in front of rotor 1

behind rotors 2 to 4 are equipped with transducers in positions 1,4 and 5 for technical reasons.

Correlation functions of the pressure signals in the different positions as indicated above were calculated and are shown as an example in Fig 13. We define

$\varphi$ - the phase of pressure oscillation in the transverse cross-sections,

$\theta$ - the geometrical angle of the pressure sensor,

$k$ - the link coefficient.

Fig. 14 indicates the relation between the phase of pressure oscillation and the geometrical position which seems to be linearly related:

$$
\varphi=k \theta
$$

with a link coefficient of

$$
k=1
$$

This value of the coefficient is in agreement with the theoretical concept of single-cell configurations of rotating stall.

\section{Conclusions}

1. The links between the frequencies of pressure oscillations and rotor speed under established rotating stall were determined by three methods:

- directly from the time diagram of the oscillation process,

- from the behavior of the pressure in space and time,

- from the signal frequency characteristics.

In all methods the links were found to have the same relations:

$$
\begin{array}{ll}
\text { for } n / n_{d}=0.6 & \omega_{i s c} / \omega_{R R}=1: 2 ; \\
\text { for } n / n_{d}=0.8 & \omega_{i s c} / \omega_{R R}=3: 7 ; \\
\text { for } n / n_{d}=0.95 & \omega_{i s c} / \omega_{R R}=3: 7 .
\end{array}
$$

2. The phases of pressure oscillation are equal to the sensor angles in the transverse cross-sections with sufficient accuracy in all cases. This is in agreement with the theoretical concept of singlecell configurations of rotating stall. 

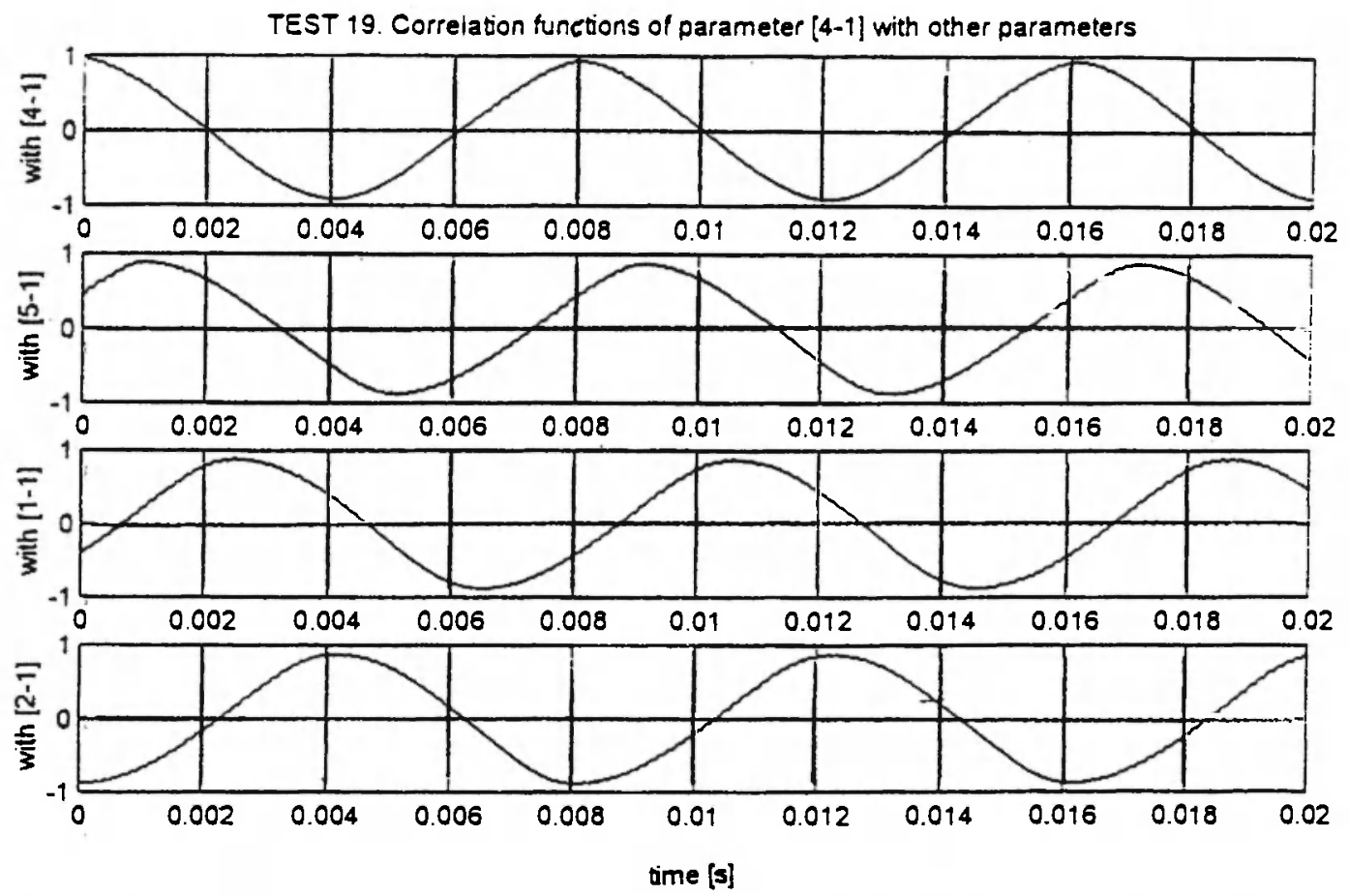

Fig. 13: Correlation functions of pressure signals of sensors in front of rotor 1 for $n / n_{d}=0.95$

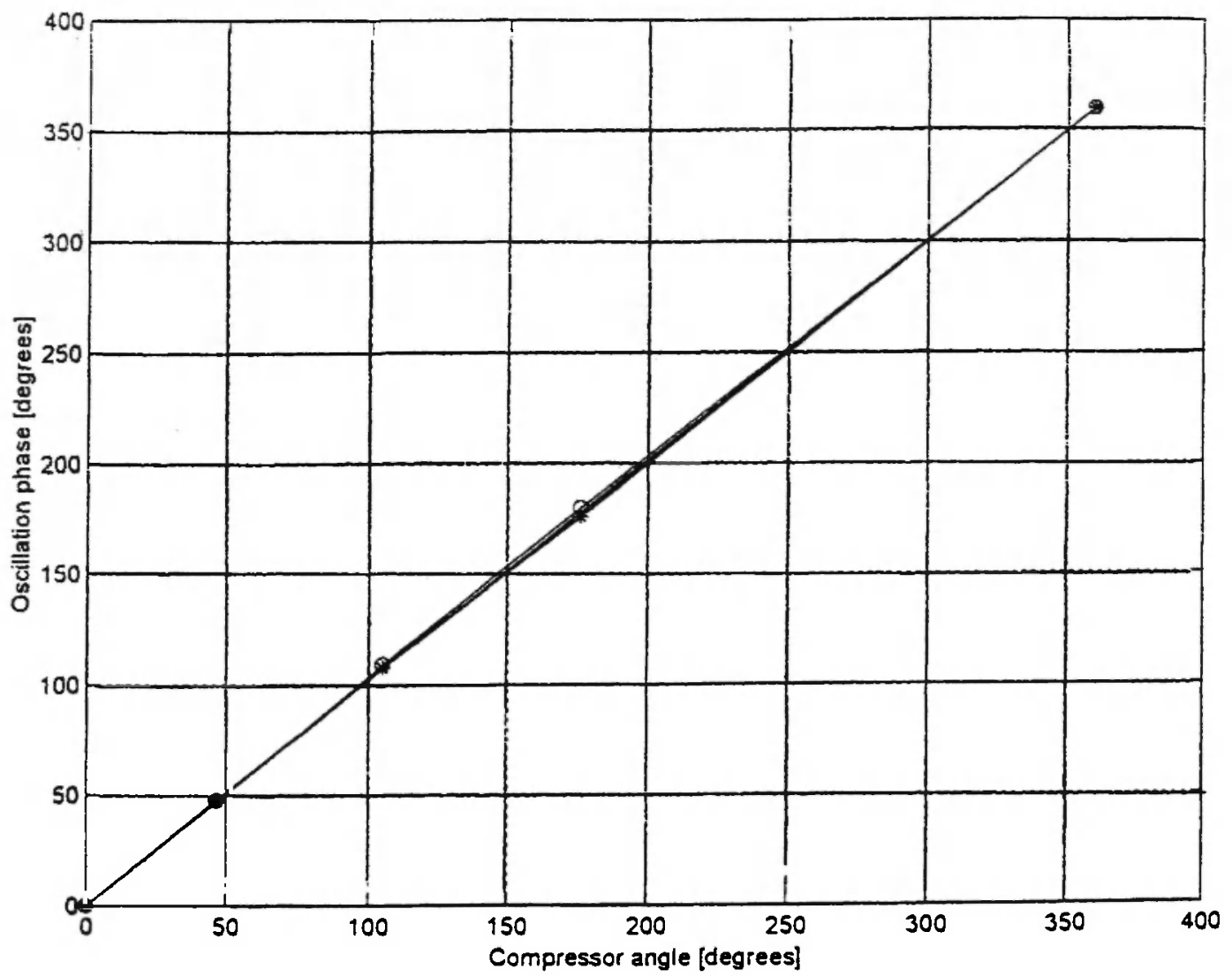

Fig. 14: Links between angles of pressure sensors in front of rotor 1 and phases of pressure oscillations 
3. It is still desirable to verify whether this feature is typical for all compressors, or is confined to this specific compressor under the present series of experiments.

\section{Acknowledgment}

The authors wish to express their gratitude to the Ministry of Sciences and Culture of Niedersachsen, Germany, Volkswagen Stiftung and the Israel Ministry of Immigrant Absorption for supporting this research.

\section{References}

1. I. Ariga, S. Masuda, and A. Ookita. "Inducer stall in a centrifugal compressor with inlet distortion", ASME Journal of Turbomachinery, 109, 27-35 (1987).

2. T.R. Camp and I.J. Day. "A study of spike and modal stall phenomena in a low-speed axial compressor", ASME Journal of Turbomachinery, 120, 393-401 (1997).

3. I.J. Day, T. Breuer, J. Escuret, M. Cherrett and A. Wilson. "Stall inception and the prospects for active control in high-speed compressors", ASME Journal of Turbomachinery, 121, 18-27 (1999).

4. I.J. Day and C. Freeman. "The unstable behavior of low and high-speed compressors", ASME Journal of Turbomachinery, 116, 194201 (1994).

5. P.B. Kahn and Y. Zarmi. Nonlinear Dynamics: Exploration Through Normal Forms, Wiley Series in Nonlinear Science, John Wiley \& Sons, Inc., 1998; p.401.

6. J. Pismenny (I.L. Pis'mennyy). "Harmonic linearization of single-valued nonlinear characteristics in the case of two-frequency oscillations", Engineering Cybernetics (Izvestiia Akademii Nauk SSR. Tekhnicheskaia Kibernetika) [English translation], 16 (1), 135. 143 (1978).

7. J. Pismenny. "Multi-frequency nonlinear oscillations in gas-turbine engine" [in Russian], Mashinostrojeniye, Moscow, Russia, 1987; p. 128.

8. J. Pismenny and Y. Levy. "On the dynamic behaviour of rotating stall", Technion Report TAE No. 847, 2000; p.26.

9. M. Rosseau. Vibration in Mechanical Systems, Springer-Verlag, Berlin-Heidelberg, 1987; p. 518.

10. M. Walbaum. "Entstehungsmechanismen und Erscheinungsformen des Rotating Stall in einem sechsstufigen Axialverdichter mit verstellbaren Leitschafeln", FortschrittBerichte VDI, Reihe 7, Nr. 352, VDI Verlag GmbH, Duesseldorf, 1999; p.140. 
Bereitgestellt von | Technische Informationsbibliothek Hannover Angemeldet Heruntergeladen am | 13.04.18 13:08 